Edith Cowan University

Research Online

Research outputs 2012

$1-1-2012$

\title{
Two maximal isometric contractions attenuate the magnitude of eccentric exercise-induced muscle damage
}

Hsin-lian Chen

Kazunori Nosaka

Edith Cowan University

Alan Pearce

Trevor C Chen

Follow this and additional works at: https://ro.ecu.edu.au/ecuworks2012

Part of the Sports Sciences Commons

10.1139/H2012-035

This is an Author's Accepted Manuscript of: Chen, H., Nosaka, K. , Pearce, A., \& Chen, T. (2012). Two maximal isometric contractions attenuate the magnitude of eccentric exercise-induced muscle damage. Applied Physiology, Nutrition and Metabolism, 37(4), 680-689. Available here

This Journal Article is posted at Research Online.

https://ro.ecu.edu.au/ecuworks2012/496 


\title{
Two maximal isometric contractions attenuate the magnitude of eccentric exercise-induced muscle damage
}

\author{
Hsin-Lian Chen, Kazunori Nosaka, Alan J. Pearce, and Trevor C. Chen
}

\begin{abstract}
This study investigated whether maximal voluntary isometric contractions (MVC-ISO) would attenuate the magnitude of eccentric exercise-induced muscle damage. Young untrained men were placed into one of the two experimental groups or one control group ( $n=13$ per group). Subjects in the experimental groups performed either two or $10 \mathrm{MVC}$-ISO of the elbow flexors at a long muscle length $\left(20^{\circ}\right.$ flexion $) 2$ days prior to 30 maximal isokinetic eccentric contractions of the elbow flexors. Subjects in the control group performed the eccentric contractions without MVC-ISO. No significant changes in maximal voluntary concentric contraction peak torque, peak torque angle, range of motion, upper arm circumference, plasma creatine kinase (CK) activity and myoglobin concentration, muscle soreness, and ultrasound echo intensity were evident after MVC-ISO. Changes in the variables following eccentric contractions were smaller $(P<0.05)$ for the 2 MVC-ISO group (e.g., peak torque loss at 5 days after exercise, $23 \% \pm 3 \%$; peak CK activity, $1964 \pm 452$ IU.L $\mathrm{L}^{-1}$; peak muscle soreness, $46 \pm 4 \mathrm{~mm})$ or the 10 MVC-ISO group $\left(13 \% \pm 3 \%, 877 \pm 198 \mathrm{IU} \cdot \mathrm{L}^{-1}, 30 \pm 4 \mathrm{~mm}\right)$ compared with the control $\left(34 \% \pm 4 \%, 6192 \pm 1747 \mathrm{IU} \cdot \mathrm{L}^{-1}, 66 \pm 5 \mathrm{~mm}\right)$. The $10 \mathrm{MVC}-\mathrm{ISO}$ group showed smaller $(P<0.05)$ changes in all variables following eccentric contractions compared with the 2 MVC-ISO group. Therefore, two MVC-ISO conferred potent protective effects against muscle damage, whereas greater protective effect was induced by $10 \mathrm{MVC}-\mathrm{ISO}$, which can be used as a strategy to minimize muscle damage.
\end{abstract}

Key words: protective effect, muscle strength, delayed onset muscle soreness, creatine kinase, elbow flexors, lengthening contractions.

Résumé : Cette étude vérifie si des contractions isométriques maximales volontaires (MVC-ISO) atténuent l'ampleur des lésions musculaires provoquées par des exercices pliométriques. On répartit de jeunes hommes non entraînés dans deux groupes expérimentaux et un groupe de contrôle à raison de 13 individus par groupe. Les sujets dans les groupes expérimentaux effectuent soit deux, soit 10 MVC-ISO des fléchisseurs du coude, muscles allongés (flexion du coude de $20^{\circ}$ ), et ce, 2 jours avant l'exercice des 30 contractions pliométriques maximales des fléchisseurs du coude en mode isokinétique. Les sujets du groupe de contrôle effectuent les contractions pliométriques sans MVC-ISO au préalable. À la suite des MVC-ISO, on n'observe aucune modification significative du moment de force miométrique maximal volontaire, de l'angle du pic du moment de force, de l'amplitude de mouvement, de la circonférence du bras, de l'activité plasmatique de la créatine kinase (CK), de la concentration de myoglobine, de la douleur musculaire et de l'intensité de l'écho de l'ultrason. Les modifications de la valeur des variables à la suite des contractions pliométriques sont plus faibles $(P<0,05)$ chez les groupes ayant effectué 2 MVC-ISO (pic du moment de force 5 jours après l'exercice, $23 \pm 3 \%$; pic de l'activité de la CK, $1964 \pm 452$ IU.L $\mathrm{L}^{-1}$; pic de la douleur musculaire, $46 \pm 4 \mathrm{~mm})$ ou $10 \mathrm{MVC}-\mathrm{ISO}\left(13 \pm 3 \%, 877 \pm 198 \mathrm{IU} \cdot \mathrm{L}^{-1}, 30 \pm 4 \mathrm{~mm}\right)$ comparativement au groupe de contrôle $\left(34 \pm 4 \%, 6192 \pm 1747 \mathrm{IU} \cdot \mathrm{L}^{-1}, 66 \pm 5 \mathrm{~mm}\right)$. Le groupe ayant effectué 10 MVC-ISO présente des modifications plus faibles $(P<0,05)$ des valeurs des variables à la suite des contractions pliométriques que le groupe ayant effectué 2 MVC-ISO. Il s'avère qu'effectuer 2 MVC-ISO est une stratégie de protection efficace contre les lésions musculaires, mais en effectuer 10 MVC-ISO, en plus d'être une plus grande protection, constitue une bonne stratégie pour minimiser les douleurs musculaires.

Mots-clés : effet protecteur, force musculaire, douleur musculaire d'apparition retardée, créatine kinase, fléchisseurs du coude, contractions pliométriques.

[Traduit par la Rédaction]

Received 4 November 2011. Accepted 9 February 2012. Published at www.nrcresearchpress.com/apnm on 11 May 2012.

H.-L. Chen and T.C. Chen. Department of Physical Education, National Chiayi University, Chiayi County 62103, Taiwan.

K. Nosaka. School of Exercise and Health Sciences, Edith Cowan University, Western Australia, Australia.

A.J. Pearce. Cognitive and Exercise Neuroscience Unit, Deakin University, Victoria, Australia.

Corresponding author: Trevor C. Chen (e-mail: trevorchen@mail.ncyu.edu.tw). 


\section{Introduction}

An unaccustomed exercise consisting of eccentric contractions induces muscle damage characterized by histological changes observed under light and (or) electron microscopy (e.g., Fridén and Lieber 2001; Lauritzen et al. 2009) and symptoms such as muscle weakness, delayed onset muscle soreness (DOMS), increased muscle stiffness, and muscle swelling, as well as increases in muscle proteins such as creatine kinase (CK) and myoglobin $(\mathrm{Mb})$ in the blood (e.g., Clarkson et al. 1992; Nosaka and Clarkson 1996). When a subsequent bout of the same or similar eccentric exercise is performed within several weeks, the changes in the muscle damage markers are attenuated and recovered to the baseline faster compared with the initial exercise bout (Clarkson et al. 1992; Black and McCully 2008; Chen et al. 2009). It seems as if a protective effect is conferred after the initial eccentric exercise bout; however, the mechanisms underpinning the protective effect are not fully understood (e.g., McHugh 2003).

The protective effect against eccentric exercise-induced muscle damage has been shown to be produced by maximal isometric contractions in animal studies (Koh and Brooks 2001; Pizza et al. 2002). For example, Koh and Brooks (2001) showed that 75 isometric contractions of mouse extensor digitorum logus (EDL) muscle at an optimum muscle length $\left(L_{\mathrm{o}}\right)$ evoked by electrical stimulation did not induce muscle damage but provided protective effect against muscle damage induced by 75 maximal eccentric contractions that were performed 14 days later. However, the effect of isometric contractions on eccentric exercise-induced muscle damage has not been investigated in humans.

We noticed from our previous studies that the recovery of muscle function was faster and changes in other muscle damage markers (e.g., muscle soreness, plasma CK activity) were smaller for the studies in which several isometric contractions were performed in a familiarization session (e.g., Chen et al. 2007, 2009) compared with the studies in which no familiarization session was included (e.g., Chen 2003; Chen and Nosaka 2006). If the magnitude of muscle damage is modified by isometric contractions performed in a familiarization session, it is important to clarify the magnitude of the effect. However, no previous study has systematically investigated the extent of the effect of maximal isometric contractions performed prior to eccentric contractions on the magnitude of eccentric exercise-induced muscle damage.

Therefore, the purpose of the present study was to investigate the effect of two and 10 maximal isometric contractions of the elbow flexors on changes in indirect muscle damage markers following 30 maximal eccentric contractions of the same muscle performed 2 days later. We hypothesized that maximal isometric contractions that were performed prior to maximal eccentric exercise would attenuate the magnitude of eccentric exercise-induced muscle damage, and 10 isometric contractions would confer greater protective effect than two isometric contractions.

\section{Methods}

\section{Subjects and study design}

Thirty-nine young men (mean \pm SD age, height, and body mass were $22.5 \pm 1.7$ years, $172.9 \pm 5.7 \mathrm{~cm}$, and $71.7 \pm$
$9.0 \mathrm{~kg}$, respectively) who had not engaged in any regular resistance, aerobic, or flexibility training in the past year and who did not carry heavy objects regularly in their daily activities participated in the present study. They had no history of previous muscle, joint, or bone injuries of the upper extremities. None of the subjects had any specific food intake habits such as caloric restriction or vegetarian, and none took nutritional supplements on a regular basis. They provided informed consent to participate in the present study that had been approved by the Institutional Ethics Committee. The present study was conducted in conformity with the policy statement regarding the use of human subjects by the Declaration of Helsinki.

The subjects were assigned to one of the three groups ( $n=$ 13 per group) by matching the baseline maximal voluntary isokinetic $\left(60^{\circ} \cdot \mathrm{s}^{-1}\right)$ concentric contraction (MVC-CON) peak torque across the groups: one control group and two experimental groups. The subjects in the two experimental groups performed either two or 10 maximal voluntary isometric contractions (2 MVC-ISO and 10 MVC-ISO, respectively) 2 days prior to maximal eccentric exercise of the elbow flexors, but the subjects in the control group performed the eccentric exercise without isometric contractions. We chose two and 10 isometric contractions, because two to 10 isometric contractions were performed in a familiarization session in the previous studies (e.g., Paddon-Jones et al. 2000; Philippou et al. 2004; Chapman et al. 2008). The interval between isometric contractions and eccentric exercise was set at 2 days based on the previous studies (Lavender and Nosaka 2008; Chen et al. 2011a) showing that nondamaging eccentric exercise conferred protective effect against maximal eccentric exercise of the elbow flexors that was performed 2 days later, and a familiarization session is generally set at a couple of days prior to eccentric exercise. All subjects used their nondominant arm for the isometric contractions and (or) eccentric exercise. No significant differences in age, height, body mass, and MVC-CON peak torque (32.7 \pm $1.7 \mathrm{~N} \cdot \mathrm{m}$ ) were evident among the groups.

The sample size was estimated using the data from a pilot study that examined the effect of 10 maximal isometric contractions of the elbow flexors at $20^{\circ}$ elbow flexion on changes in MVC-CON peak torque following 30 maximal eccentric contractions that were performed 2 days later. From the pilot study data, it was estimated that a difference of at least $10 \%$ would exist for the peak torque recovery at 5 days after the eccentric contractions between the eccentric exercises with and without the isometric contractions prior to the exercises. The MVC-CON peak torque was used for the sample size estimation, as muscle function measure is considered to be the best marker of muscle damage (Clarkson et al. 1992; Warren et al. 1999). Based on the effect size of 1 , $\alpha$ level of 0.05 , and a power $(1-\beta)$ of 0.80 (Cohen 1988), it was estimated that minimum 12 subjects per group were necessary.

The subjects were requested and reminded to avoid any vigorous physical activities or unaccustomed exercise, to maintain their normal dietary and sleep habits, and not to take any anti-inflammatory drugs (e.g., nonsteroid anti-inflammatory drugs) or nutritional supplements (e.g., vitamins, protein or amino acids) for 2 weeks before and during the experimental period. The subjects were instructed and reminded to drink 
sufficient water following eccentric exercise to avoid a potential risk of acute renal failure due to rhabdomyolysis, refrain from alcohol and caffeine, and not to have any treatments of the exercised muscles (e.g., massage, stretching) during the experimental period. The investigator asked the subjects to report if they were not able to follow the above requirements or instructions.

\section{Experimental protocol}

The maximal isometric and eccentric exercise and postexercise measurements were performed in the morning (0800 and 1200), and each subject performed the exercise and the measurements within a $2 \mathrm{~h}$ difference across days. The subjects were familiarized with the testing procedures 3 days before the first exercise bout (either isometric contractions or eccentric exercise). In the familiarization session, height and body mass were measured, and the investigator took upper arm circumference, muscle soreness, range of motion, and MVC-CON torque $\left(60^{\circ} \cdot \mathrm{s}^{-1}\right)$ measurements. The investigator demonstrated to the subjects how to perform isometric and eccentric contractions but no actual isometric and eccentric contractions were performed by the subjects, as they were thought to affect the results.

The dependent variables included MVC-CON peak torque, peak torque angle, range of motion (ROM), upper arm circumference, plasma $\mathrm{CK}$ activity and $\mathrm{Mb}$ concentration, muscle soreness assessed by visual analog scale (VAS), and echo intensity of the B-mode ultrasound images. These variables were used in our previous studies investigating protective effect against eccentric exercise-induced muscle damage (e.g., Chen et al. 2011a, 2011b). All of these measurements except plasma $\mathrm{CK}$ activity and $\mathrm{Mb}$ concentration were taken from the exercised arm; blood samples were taken from the other arm for the analyses of plasma $\mathrm{CK}$ activity and $\mathrm{Mb}$ concentration. MVC-CON peak torque, peak torque angle, ROM, and upper arm circumference measures were taken 2 days and immediately before, immediately after, and 1 and 2 days after the isometric contractions and immediately before, immediately after, and 1-10 days after the eccentric exercise. Plasma $\mathrm{CK}$ activity and $\mathrm{Mb}$ concentration, muscle soreness, and echo intensity were measured at all time points shown above except immediately after exercise. The two baseline measurements were taken at 2 days and immediately before the isometric contractions for the 2 MVC-ISO and 10 MVC-ISO groups or the eccentric exercise for the control group (13 subjects $\times$ three groups). The test-retest reliability of the dependent variable measurements between the above two baseline measures was determined by an intraclass correlation coefficient $(R)$ and coefficient of variation (CV). The $R$ and $\mathrm{CV}$ (shown in parentheses) values for MVC-CON peak torque, peak torque angle, ROM, upper arm circumference, muscle soreness, plasma CK activity and $\mathrm{Mb}$ concentration, and echo intensity were 0.98 (8.5\%), 0.95 (7.8\%), 0.98 (4.8\%), 0.99 (6.4\%), 1.00 (0\%), $0.93(7.4 \%), 0.93(7.8 \%)$, and $0.97(7.4 \%)$, respectively.

\section{Isometric contractions}

The subjects in the 2 MVC-ISO and 10 MVC-ISO groups performed two and 10 maximal isometric contractions of the elbow flexors, respectively, at an elbow angle of $20^{\circ}$ elbow flexion (full elbow extension $=0^{\circ}$ ) 2 days prior to maximal eccentric exercise. Each subject was seated upright on a chair, and his chest and waist were immobilized by straps, placing the upper arm on a padded support that secured the shoulder joint angle at $45^{\circ}$ flexion and $0^{\circ}$ abduction. The elbow joint was set at $20^{\circ}$ with the forearm in a fully supinated position, and the wrist was strapped to the lever attachment of an isokinetic dynamometer (Biodex System 3 Pro, Biodex Medical Systems, Inc., Shirley, New York, USA). The subjects were asked to start contracting as soon as the investigator said "go" at the beginning of each isometric contraction and were asked to contract maximally for $3 \mathrm{~s}$. The isometric contraction was repeated every $45 \mathrm{~s}$ for two and 10 times for the 2 MVC-ISO and 10 MVC-ISO groups, respectively. Strong verbal encouragement was given to the subjects during the contractions. The torque signals during the maximal isometric contractions were monitored and saved in a desktop computer (AcerPower FH, Acer Inc., Taiwan) that was connected to the isokinetic dynamometer, and peak torque of each contraction was obtained using a software of the Biodex Medical Systems (Systems 3 Application Software for Window XP).

\section{Eccentric exercise}

The subject's setup for the eccentric exercise was the same as that of the isometric contraction protocol described above. The eccentric exercise consisted of five sets of six maximal eccentric contractions of the elbow flexors at an angular velocity of $90^{\circ} \cdot \mathrm{s}^{-1}$ from a half-flexed position $\left(90^{\circ}\right)$ to a fully extended position on the isokinetic dynamometer (Chen et al. 2009). Each contraction lasted for $1 \mathrm{~s}$ and was repeated every $10 \mathrm{~s}$ during which the isokinetic dynamometer passively returned the elbow joint to the flexed position at the velocity of $9^{\circ} \cdot \mathrm{s}^{-1}$, with a 2 -min rest between sets. Subjects were verbally encouraged to maximally resist the movements of the isokinetic dynamometer to extend the elbow joint. The torque and elbow joint angle position signals of each contraction were saved in the desktop computer connected to the isokinetic dynamometer as described above, and peak torque and work (the area under the torque curve) of each contraction were calculated using the Biodex software. The average torque of each set was obtained and used for subsequent analysis.

\section{Dependent variables}

\section{MVC-CON peak torque and peak torque angle}

MVC-CON peak torque and peak torque angle were measured by the same isokinetic dynamometer in the same position as that described for the isometric contractions. MVC$\mathrm{CON}$ peak torque was measured at the angular velocity of $60^{\circ} \cdot \mathrm{s}^{-1}$ for the range of motion of $140^{\circ}$ for the elbow flexors $\left(0^{\circ}-140^{\circ}\right)$ and extensors $\left(140^{\circ}-0^{\circ}\right)$ for three continuous contractions for both directions. The angular velocity was based on our previous studies (Chen et al. 2011a, 2011b) in which the peak torque angle of the elbow flexors was examined. Verbal encouragement was provided during the tests. The torque and the elbow joint angle signals of each contraction were saved in a computer connected to the isokinetic dynamometer. The torque raw data were filtered and smoothed using an "isokinetic windowing," which removed torque values outside nonisokinetic phases, and the "nine-point weighted 
smooth filter" function of the software program of the Biodex Medical Systems, and the peak torque and the joint angle of the peak torque (peak torque angle) were assessed by the software. The highest values of the three trials for the elbow flexor and extensor MVC-CON peak torque were used for further analysis, and the average of the three trials for the peak torque angle of the elbow flexors was used for subsequent analysis (Chen et al. 2011b).

\section{Elbow joint angles and ROM}

ROM of the elbow joint was determined as the difference between the elbow joint angles of maximal voluntarily flexion (FANG) and extension (EANG). The FANG was measured when the subject maximally flexed the elbow joint to touch his shoulder of the same side, and the EANG was measured when the subject attempted to extend his elbow joint as much as possible with the elbow held by his side and the hand in midpronation while standing. A plastic goniometer was used for the measurements, three measurements were taken for each angle, and the average of the three measurements was used to calculate ROM (Lavender and Nosaka 2008; Chen et al. 2009).

\section{Upper arm circumference}

The upper arm circumference was measured at the midportion of the upper arm, between the acromion process of the clavicle to the lateral epicondyle of the humerus, using a $\mathrm{Gu}$ lick tape measure (Creative Health Products, Plymouth, Michigan, USA), while the subject was relaxing and letting the arm hang down by his side. The perimeter distance of the upper arm perpendicular to the long axis of the humerus was measured from the midportion marked by a semipermanent ink pen (Hawes and Martin 2001). The measurements were taken three times, and the average of the three measures was used for statistical analysis. The same examiner took all measurements.

\section{Muscle soreness}

Muscle soreness of the elbow flexors was quantified using a visual analogue scale that had a $100 \mathrm{~mm}$ continuous line with "no pain at all" on one end $(0 \mathrm{~mm})$ and "unbearable pain" on the other end $(100 \mathrm{~mm})$. The subjects were asked to rate their perceived soreness on the visual analogue scale when the elbow joint was passively extended and flexed, respectively, for the range of motion used for the MVC-CON peak torque measurements (Chen et al. 2011a, 2011b).

\section{Plasma CK activity and Mb concentration}

Approximately $5 \mathrm{~mL}$ of venous blood was drawn from the antecubital vein of the dominant arm using a standard venipuncture technique and centrifuged for $10 \mathrm{~min}$ to separate the plasma, and plasma samples were stored at $-80{ }^{\circ} \mathrm{C}$ for later analyses. Plasma CK activity was assayed via spectrophotometry by an automated clinical chemistry analyzer (model 7080, Hitachi, Co. Ltd., Tokyo, Japan) using commercially available test kits (Roche Diagnostics, Indianapolis, Indiana, USA). Plasma Mb concentration was measured by an automated clinical chemistry analyzer (model Elecsys 2010, Roche Diagnostics GmbH, Mannheim, Germany) using a commercial test kit (Roche Diagnostics). Each sample was analyzed in duplicate, and the average value of two measures was used for subsequent statistical analysis. The normal reference range for adult men provided by the manufacturers of the kits was $38-174 \mathrm{IU} \cdot \mathrm{L}^{-1}$ for plasma CK activity and $<110 \mu \mathrm{g} \cdot \mathrm{L}^{-1}$ for $\mathrm{Mb}$ concentration.

\section{Ultrasonography}

Transverse B-mode ultrasound images were taken using a Terason $\mathrm{t} 3000$ Ultrasound System with a $7.5 \mathrm{MHz}$ linear probe (Terason Co., Burlington, Massachusetts, USA) and saved in a computer (HP workstation xw4400, Hewlett-Packard Company, Singapore). The probe was placed at the midportion of the biceps brachii (the same site of the circumference measurement) while the subject was sitting on a chair with the forearm on a padded table at the shoulder angle of $80^{\circ}$ and the elbow joint angle of $10^{\circ}$ for the elbow flexor measures. Placement of the ultrasound probe and the volume of the ultrasound gel were standardized, and the same investigator took all images. The transverse images were obtained from the same sites over time, and the setting of the ultrasound machine (e.g., focus, gain, and contrast) was unchanged over days. The echo intensity was analyzed by computer image analysis software (ULT File Reader for Windows, Broadsound Co., Taiwan), and the mean echo intensity of a histogram of gray scale (0, black; 256, white) was calculated for the region of interest (ROI, $2 \times 2=$ $4 \mathrm{~cm}^{2}$ ) based on the previous study (Chen et al. 2009). The relative change in the echo intensity from the pre-exercise value was calculated.

\section{Statistical analyses}

Data were assessed by a Shapiro-Wilk test for the normality and a Levene test for the homogeneity of variance assumption. These tests showed that the data of all dependent variables were normally distributed, the cases were independent, and the variance was homogenous. Baseline values for all dependent variables before the first exercise bout (two and 10 maximal isometric contractions for the 2 MVC-ISO and 10 MVC-ISO groups, respectively, and maximal eccentric exercise for the control group) and before the maximal eccentric exercise were compared among 2 MVC-ISO, 10 MVC-ISO, and control groups by a one-way analysis of variance (ANOVA). Changes in the dependent variables following isometric contractions were compared between the 2 MVC-ISO and 10 MVC-ISO groups by a two-way repeatedmeasures ANOVA. Changes in the dependent variables following eccentric exercise were compared among the three groups (2 MVC-ISO, 10 MVC-ISO, and control groups) by a two-way repeated-measures ANOVA. Changes in peak torque over two and 10 maximal isometric contractions were analysed by a one-way repeated-measures ANOVA. Changes in peak torque and work during maximal eccentric exercise were also compared among the groups (2 MVC-ISO, 10 MVC-ISO, and control groups) by a two-way repeatedmeasures ANOVA. When a significant interaction effect was found, a series of two-way ANOVAs were performed to compare between two groups (2 MVC-ISO and 10 MVC-ISO, 2 MVC-ISO and control, 10 MVC-ISO and control). When the ANOVA found a significant interaction effect, a Tukey's post-hoc test was performed for the comparison between groups for each time point. A significant level was set at $P \leq 0.05$. The data are presented as mean \pm SEM, unless otherwise stated. 


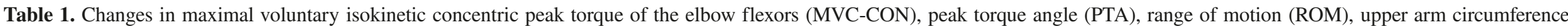
(CIR), plasma creatine kinase (CK) activity and myoglobin (Mb) concentration, muscle soreness with passive flexion (SOR-Fle) and extension (SOR-Ext), and echo intensity of the Bmode ultrasound images before (pre), immediately after (post), and 1 day (d1) and 2 days (d2) after the two and 10 maximal isometric contractions (2 MVC-ISO and 10 MVC-ISO, respectively).

\begin{tabular}{|c|c|c|c|c|c|}
\hline & Group & Pre & Post & d1 & $\mathrm{d} 2$ \\
\hline \multirow[t]{2}{*}{$\mathrm{MVC}-\mathrm{CON}(\mathrm{N} \cdot \mathrm{m})$} & 2 MVC-ISO & $\begin{array}{l}33.4 \pm 1.6 \\
(30.6-36.3)\end{array}$ & $\begin{array}{l}32.6 \pm 1.7 \\
(29.5-35.7)\end{array}$ & $\begin{array}{l}32.8 \pm 1.7 \\
(29.7-35.9)\end{array}$ & $\begin{array}{l}33.4 \pm 1.7 \\
(30.4-34.4)\end{array}$ \\
\hline & 10 MVC-ISO & $\begin{array}{l}32.5 \pm 2.1 \\
(28.8-36.3)\end{array}$ & $\begin{array}{l}32.1 \pm 2.0 \\
(28.5-35.7)\end{array}$ & $\begin{array}{l}32.5 \pm 2.0 \\
(28.9-36.1)\end{array}$ & $\begin{array}{l}33.1 \pm 1.9 \\
(29.7-36.5)\end{array}$ \\
\hline \multirow[t]{2}{*}{ PTA $\left(^{\circ}\right)$} & 2 MVC-ISO & $\begin{array}{l}78.8 \pm 2.0 \\
(76.5-81.2)\end{array}$ & $\begin{array}{l}77.7 \pm 2.2 \\
(75.0-80.4)\end{array}$ & $\begin{array}{l}78.0 \pm 2.0 \\
(75.5-80.4)\end{array}$ & $\begin{array}{l}78.2 \pm 2.2 \\
(75.5-81.0)\end{array}$ \\
\hline & 10 MVC-ISO & $\begin{array}{l}77.6 \pm 2.3 \\
(73.3-82.0)\end{array}$ & $\begin{array}{l}77.0 \pm 2.4 \\
(72.5-81.5)\end{array}$ & $\begin{array}{l}76.1 \pm 2.3 \\
(71.7-80.5)\end{array}$ & $\begin{array}{l}77.4 \pm 2.4 \\
(72.8-82.0)\end{array}$ \\
\hline \multirow[t]{2}{*}{$\operatorname{ROM}\left(^{\circ}\right)$} & 2 MVC-ISO & $\begin{array}{l}142.7 \pm 1.3 \\
(139.6-145.9)\end{array}$ & $\begin{array}{l}142.6 \pm 1.2 \\
(139.6-145.6)\end{array}$ & $\begin{array}{l}142.2 \pm 1.2 \\
(139.2-145.2)\end{array}$ & $\begin{array}{l}143.0 \pm 1.3 \\
(140.0-146.1)\end{array}$ \\
\hline & 10 MVC-ISO & $\begin{array}{l}142.8 \pm 1.4 \\
(138.5-147.0)\end{array}$ & $\begin{array}{l}142.4 \pm 1.4 \\
(138.3-146.5)\end{array}$ & $\begin{array}{l}142.5 \pm 1.5 \\
(138.3-146.6)\end{array}$ & $\begin{array}{l}142.8 \pm 1.6 \\
(138.1-147.5)\end{array}$ \\
\hline \multirow[t]{2}{*}{ CIR (mm) } & 2 MVC-ISO & $\begin{array}{l}275.1 \pm 5.0 \\
(262.9-287.2)\end{array}$ & $\begin{array}{l}275.3 \pm 4.9 \\
(263.3-287.3)\end{array}$ & $\begin{array}{l}275.2 \pm 4.9 \\
(263.2-287.2)\end{array}$ & $\begin{array}{l}275.5 \pm 5.0 \\
(263.5-287.5)\end{array}$ \\
\hline & 10 MVC-ISO & $\begin{array}{l}275.2 \pm 5.4 \\
(258.7-291.7)\end{array}$ & $\begin{array}{l}275.4 \pm 5.5 \\
(258.9-291.9)\end{array}$ & $\begin{array}{l}275.4 \pm 5.5 \\
(258.9-292.0)\end{array}$ & $\begin{array}{l}275.3 \pm 5.3 \\
(259.3-291.4)\end{array}$ \\
\hline \multirow[t]{2}{*}{ CK (IU/L) } & 2 MVC-ISO & $\begin{array}{l}114.9 \pm 6.6 \\
(95.0-134.9)\end{array}$ & - & $\begin{array}{l}115.6 \pm 7.6 \\
(92.7-138.5)\end{array}$ & $\begin{array}{l}118.4 \pm 8.6 \\
(101.3-133.9)\end{array}$ \\
\hline & 10 MVC-ISO & $\begin{array}{l}113.4 \pm 7.6( \\
90.6-136.2)\end{array}$ & - & $\begin{array}{l}115.7 \pm 7.8 \\
(92.0-139.4)\end{array}$ & $\begin{array}{l}116.2 \pm 6.5 \\
(101.9-130.4)\end{array}$ \\
\hline \multirow[t]{2}{*}{$\mathrm{Mb}(\mu \mathrm{g} / \mathrm{L})$} & 2 MVC-ISO & $\begin{array}{l}25.1 \pm 0.9 \\
(22.3-27.9)\end{array}$ & - & $\begin{array}{l}25.5 \pm 1.0 \\
(21.3-28.6)\end{array}$ & $\begin{array}{l}27.0 \pm 1.2 \\
(20.5-30.6)\end{array}$ \\
\hline & 10 MVC-ISO & $\begin{array}{l}27.3 \pm 1.4 \\
(21.0-31.6)\end{array}$ & - & $\begin{array}{l}26.5 \pm 1.2 \\
(20.1-30.0)\end{array}$ & $\begin{array}{l}26.3 \pm 1.1 \\
(20.9-30.9)\end{array}$ \\
\hline \multirow[t]{2}{*}{ SOR-Fle $(\mathrm{mm})$} & 2 MVC-ISO & $\begin{array}{l}0.0 \pm 0.0 \\
(0.0-0.0)\end{array}$ & - & $\begin{array}{l}0.1 \pm 0.1 \\
(0.1-0.3)\end{array}$ & $\begin{array}{l}0.1 \pm 0.1 \\
(0.1-0.3)\end{array}$ \\
\hline & 10 MVC-ISO & $\begin{array}{l}0.0 \pm 0.0 \\
(0.0-0.0)\end{array}$ & - & $\begin{array}{l}0.5 \pm 0.2 \\
(0.1-1.0)\end{array}$ & $\begin{array}{l}1.9 \pm 0.7 \\
(0.1-2.9)\end{array}$ \\
\hline \multirow[t]{2}{*}{ SOR-Ext (mm) } & 2 MVC-ISO & $\begin{array}{l}0.0 \pm 0.0 \\
(0.0-0.0)\end{array}$ & - & $\begin{array}{l}0.1 \pm 0.1 \\
(0.1-0.3)\end{array}$ & $\begin{array}{l}0.3 \pm 0.2 \\
(0.1-0.7)\end{array}$ \\
\hline & 10 MVC-ISO & $\begin{array}{l}0.0 \pm 0.0 \\
(0.0-0.0)\end{array}$ & - & $\begin{array}{l}0.7 \pm 0.3 \\
(0.3-1.0)\end{array}$ & $\begin{array}{l}3.8 \pm 1.0 \\
(0.7-5.9)\end{array}$ \\
\hline \multirow[t]{2}{*}{ Echo intensity (A.U.) } & 2 MVC-ISO & $\begin{array}{l}62.1 \pm 2.0 \\
(55.5-68.8)\end{array}$ & - & $\begin{array}{l}63.8 \pm 1.8 \\
(58.4-69.2)\end{array}$ & $\begin{array}{l}65.7 \pm 1.9 \\
(60.1-71.3)\end{array}$ \\
\hline & 10 MVC-ISO & $\begin{array}{l}60.0 \pm 1.2 \\
(54.8-65.2)\end{array}$ & - & $\begin{array}{l}60.3 \pm 1.5 \\
(55.7-65.0)\end{array}$ & $\begin{array}{l}62.0 \pm 1.0 \\
(58.4-65.6)\end{array}$ \\
\hline
\end{tabular}

Note: No significant changes in any of the dependent variables were seen following two and 10 maximal isometric contractions. The mean \pm SEM and $95 \%$ confidence interval values (in parentheses) of the 2 MVC-ISO and 10 MVC-ISO groups ( $n=13$ per group) are shown. 


\section{Results}

\section{Changes in dependent variables following isometric contractions}

No significant differences in the baseline measures were evident between 2 MVC-ISO and 10 MVC-ISO groups. No significant changes in peak torque were seen over two or 10 maximal isometric contractions. The average peak torque produced during the maximal isometric contractions was $25.6 \pm 1.1 \mathrm{~N} \cdot \mathrm{m}$ for $2 \mathrm{MVC}-\mathrm{ISO}$ and $23.5 \pm 1.4 \mathrm{~N} \cdot \mathrm{m}$ for 10 MVC-ISO, and no significant difference was evident between the groups. No significant changes in any variables were evident after two and 10 maximal isometric contractions, and no significant differences between groups were seen (Table 1).

\section{Changes in dependent variables following eccentric exercise}

\section{Eccentric exercise}

Figure 1 illustrates the changes in average peak torque and work of each set (six contractions) over five sets. No significant differences in the changes in peak torque and work were evident among the groups. Both peak torque and work decreased significantly over five sets, and compared with the first set, the peak torque and work were $20.1 \% \pm 2.7 \%$ and $25.1 \% \pm 3.0 \%$ lower in the fifth set, respectively.

\section{MVC-CON peak torque and peak torque angle}

No significant differences in MVC-CON peak torque of the elbow flexors (control, $34.4 \pm 1.0 \mathrm{~N} \cdot \mathrm{m} ; 2 \mathrm{MVC}-\mathrm{ISO}$, $32.9 \pm 1.0 \mathrm{~N} \cdot \mathrm{m} ; 10 \mathrm{MVC}-\mathrm{ISO}, 33.5 \pm 1.1 \mathrm{~N} \cdot \mathrm{m})$ and extensors (control, $36.4 \pm 1.2 \mathrm{~N} \cdot \mathrm{m} ; 2 \mathrm{MVC}-\mathrm{ISO}, 36.5 \pm 1.0 \mathrm{~N} \cdot \mathrm{m}$; 10 MVC-ISO, $35.4 \pm 1.2 \mathrm{~N} \cdot \mathrm{m}$ ) were observed among the groups before eccentric exercise. No significant changes in the elbow extensor MVC-CON peak torque were evident following eccentric exercise for any of the groups. Figure $2 a$ illustrates normalized changes in elbow flexors MVC-CON peak torque from baseline $(100 \%)$ immediately after and for 10 days after maximal eccentric exercise for all groups. No significant difference in the decrease in MVC-CON peak torque immediately after eccentric exercise was seen among the 2 MVC-ISO $(45.4 \% \pm 2.0 \%), 10$ MVC-ISO $(43.6 \% \pm 2.0 \%)$, and control $(48.1 \% \pm 2.7 \%)$ groups. However, the recovery of MVC-CON peak torque was significantly faster for the 2 MVC-ISO and 10 MVC-ISO groups compared with the control group. When comparing the 2 MVC-ISO and $10 \mathrm{MVC}-$ ISO groups, MVC-CON peak torque recovered significantly faster for the $10 \mathrm{MVC}$-ISO group (returned to the baseline by 7 days) when compared with the 2 MVC-ISO group ( 9 days). The MVC-CON peak torque at 5 days after exercise, which indicates a recovery, was enhanced by $17 \%$ for the 2 MVC-ISO group and $31 \%$ for the 10 MVC-ISO group compared with the control group.

At baseline, no significant difference in the peak torque angle was evident among the groups (control, $76.2 \pm 2.3^{\circ} ; 2$ MVC-ISO, $78.2 \pm 2.0^{\circ} ; 10$ MVC-ISO, $77.4 \pm 2.4^{\circ}$, where fully extended elbow joint angle is $0^{\circ}$ ). As illustrated in Fig. $2 b$, the peak torque angle significantly shifted to a longer muscle length following eccentric exercise for all groups, but the magnitude of the shift was significantly greater for the control group compared with the 10 MVC-ISO group.
Fig. 1. Changes (mean \pm SEM) in $(a)$ peak torque and $(b)$ work over five sets (mean value of six maximal eccentric contractions) for the control $(\mathrm{CON})$ and experimental groups that performed either two or 10 maximal isometric contractions (2 MVC-ISO and 10 MVC-ISO, respectively) prior to eccentric exercise. No significant difference was evident among the groups.

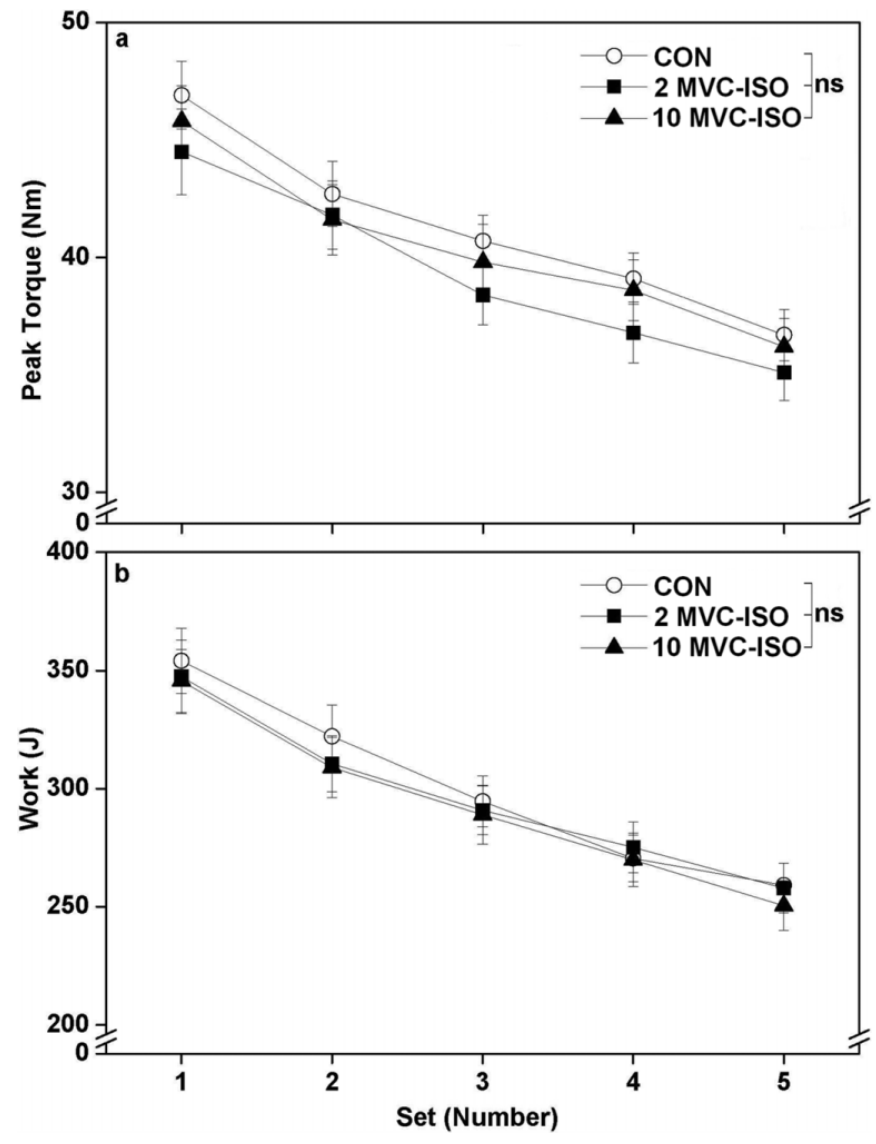

The magnitude of maximal change in peak torque angle after exercise was $34 \%$ smaller for the 10 MVC-ISO group when compared with the control group.

\section{ROM and upper arm circumference}

No significant difference in ROM before eccentric exercise was found among the groups (control, $142.4 \pm 1.2^{\circ} ; 2 \mathrm{MVC}$ ISO, $143.0 \pm 1.3^{\circ} ; 10 \mathrm{MVC}-\mathrm{ISO}, 142.8 \pm 1.4^{\circ}$ ). The magnitude of decrease in ROM immediately after eccentric exercise was not significantly different among the 2 MVC-ISO $\left(12.8 \pm 1.5^{\circ}\right), 10$ MVC-ISO (12.2 $\left.\pm 1.6^{\circ}\right)$, and control $\left(13.8 \pm 1.7^{\circ}\right)$ groups (Fig. $\left.3 a\right)$. However, compared with the control group, the recovery of ROM was significantly faster for the 2 MVC-ISO and 10 MVC-ISO groups, with a significant faster recovery for the 10 MVC-ISO group than for the 2 MVC-ISO group. The recovery of ROM, which is represented at 5 days after exercise, was enhanced by $40 \%$ for the 2 MVC-ISO group and $61 \%$ for the 10 MVC-ISO group compared with the control group.

Regarding the upper arm circumference, no significant difference was observed before eccentric exercise among the 2 MVC-ISO, 10 MVC-ISO, and control groups, and the average upper arm circumference before exercise was $275.3 \pm$ $4.9 \mathrm{~mm}$. The amount of increase in the upper arm circumference 
Fig. 2. Normalized changes (mean \pm SEM) in (a) maximal voluntary isokinetic concentric contraction peak torque of the elbow flexors (MVC-CON peak torque) from the baseline (pre, 100\%) and (b) the amount of change in peak torque angle from the baseline (pre, 0), immediately after (post), and 1-10 days after eccentric exercise of the elbow flexors for the control group (CON) and experimental groups that performed either two or 10 maximal isometric contractions (2 MVC-ISO and 10 MVC-ISO, respectively) prior to eccentric exercise. An asterisk $\left(^{*}\right)$ indicates a significant difference $(P<0.05)$ between groups based on the interaction effect shown by the two-way repeated-measures ANOVA. The relative MVC-CON peak torque values to the baseline at 5 days after exercise for the three groups are indicated in $a$. The maximal changes in peak torque angle from baseline for the three groups are indicated in $b$.

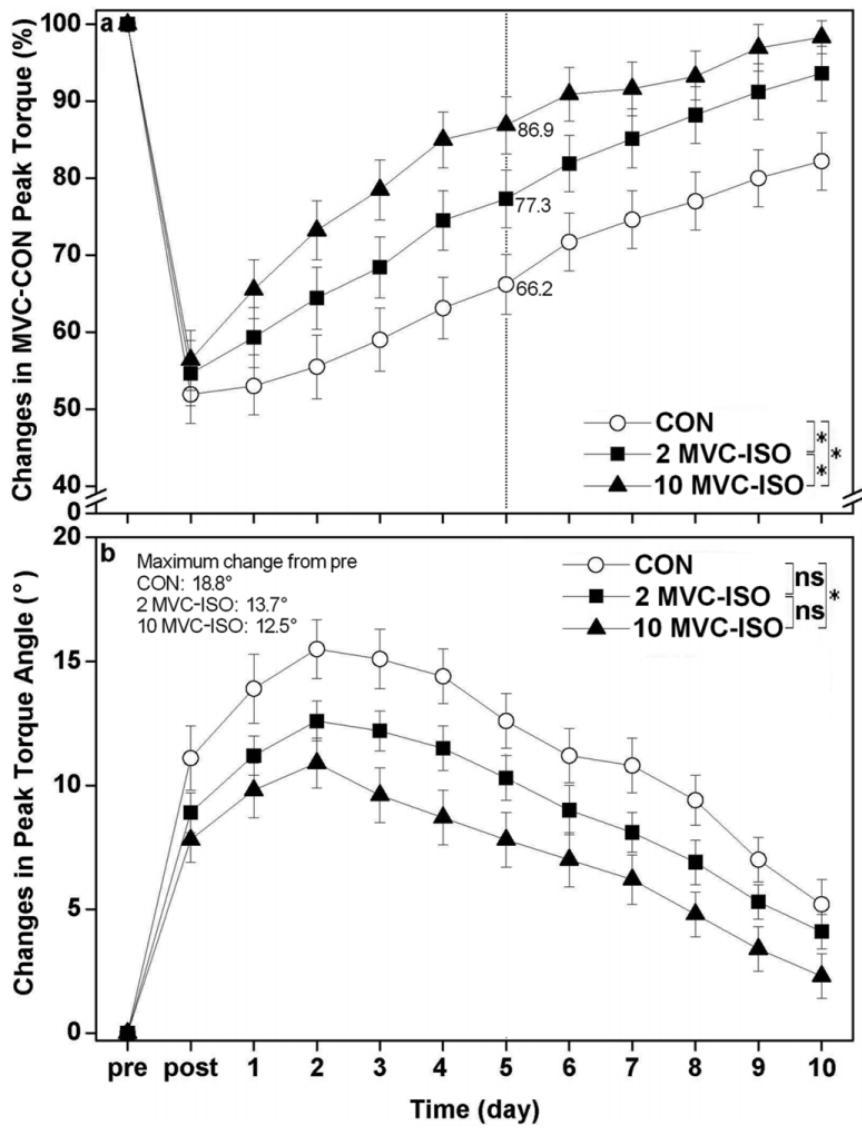

from the baseline value was significantly smaller for the 2 MVC-ISO and 10 MVC-ISO groups compared with the control group, and the 10 MVC-ISO group showed significantly smaller increases compared with the 2 MVC-ISO group (Fig. 3b). The increases in the circumference at 5 days after exercise, where the largest increases were seen, was attenuated by $29 \%$ for the 2 MVC-ISO group and $60 \%$ for the 10 MVC-ISO group compared with the control group.

\section{Plasma CK activity and $\mathrm{Mb}$ concentration}

Baseline values of $\mathrm{CK}$ activity and $\mathrm{Mb}$ concentration were similar across groups, and the average $\mathrm{CK}$ activity and $\mathrm{Mb}$ concentration before exercise were $120.9 \pm 5.3 \mathrm{IU} \cdot \mathrm{L}^{-1}$ and $25.8 \pm 1.1 \mu \mathrm{g} \cdot \mathrm{L}^{-1}$, respectively. As illustrated in Fig. 4, the increases in plasma $\mathrm{CK}$ activity and $\mathrm{Mb}$ concentration fol-
Fig. 3. The amount of changes (mean \pm SEM) in (a) range of motion (ROM) and $(b)$ upper arm circumference from the baseline (pre, 0 ), immediately after (post), and 1-10 days after eccentric exercise for the control group $(\mathrm{CON})$ and experimental groups that performed either two or 10 maximal isometric contractions (2 MVCISO and 10 MVC-ISO, respectively) prior to eccentric exercise. An asterisk $(*)$ indicates a significant difference $(P<0.05)$ between groups based on the interaction effect shown by the two-way repeated-measures ANOVA. The values at 5 days after exercise for the three groups are indicated in both figures.

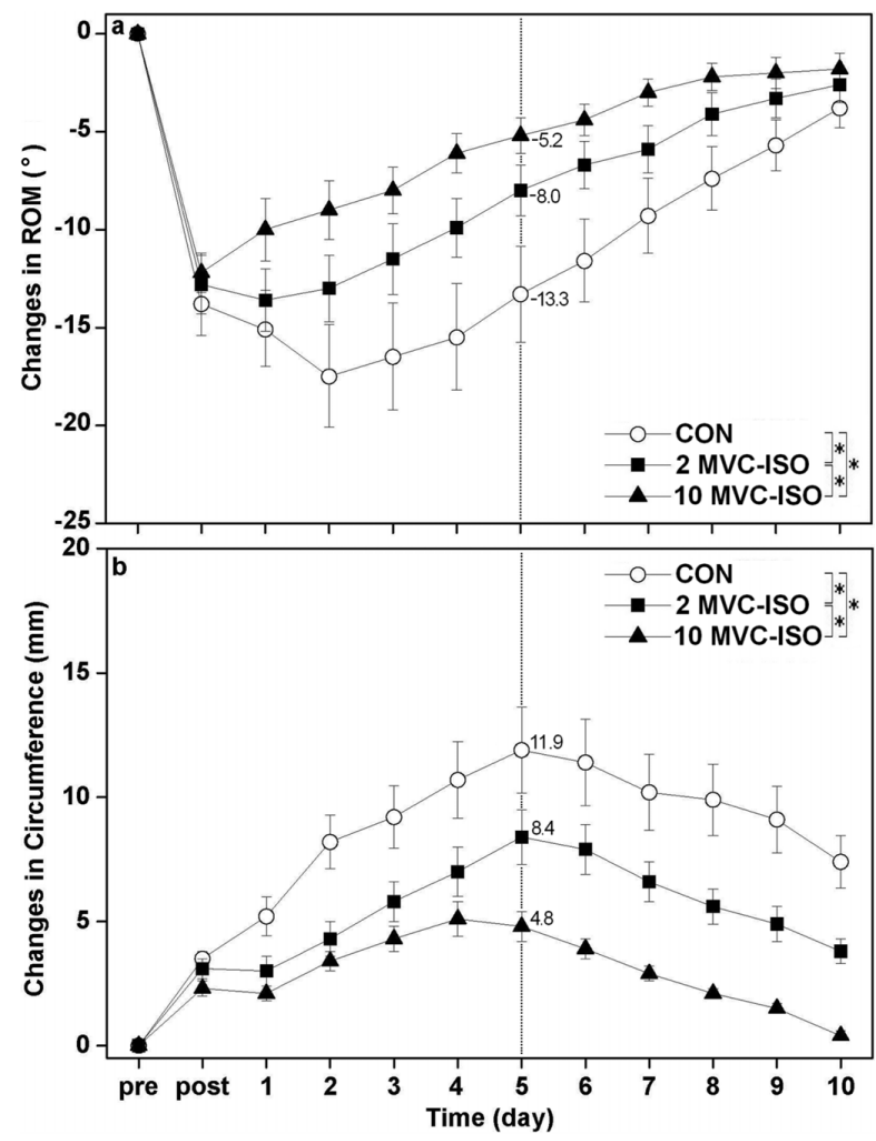

lowing eccentric exercise were significantly smaller for the 2 MVC-ISO and 10 MVC-ISO groups compared with the control group, and the increases were significantly smaller for the 10 MVC-ISO group compared with the 2 MVC-ISO group. The peak $\mathrm{CK}$ activity and $\mathrm{Mb}$ concentration were attenuated in the 2 MVC-ISO ( $68 \%$ for $\mathrm{CK}$ and $61 \%$ for $\mathrm{Mb}$ ) and 10 MVC-ISO (86\% for CK, $78 \%$ for $\mathrm{Mb}$ ) groups compared with the control group.

\section{Muscle soreness and echo intensity}

No muscle soreness was evident before exercise. Muscle soreness with passive extension of the elbow flexors after eccentric exercise was significantly smaller for the 2 MVC-ISO and 10 MVC-ISO groups compared with the control group (Fig. 5a). The 10 MVC-ISO group showed significantly less muscle soreness than the 2 MVC-ISO group. The peak soreness was reduced by $30 \%$ for the 2 MVC-ISO group and by $55 \%$ for the 10 MVC-ISO group compared with the control group. Similar results were found for the muscle soreness with passive flexion of the elbow flexors. 
Fig. 4. Changes (mean \pm SEM) in (a) plasma creatine kinase (CK) activity and (b) myoglobin $(\mathrm{Mb})$ concentration before (pre) and 110 days after eccentric exercise for the control group (CON) and experimental groups that performed either two or 10 maximal isometric contractions (2 MVC-ISO and 10 MVC-ISO, respectively) prior to eccentric exercise. An asterisk (*) indicates a significant difference $(P<0.05)$ between groups based on the interaction effect shown by the two-way repeated-measures ANOVA. Peak CK activity and peak $\mathrm{Mb}$ concentration of the three groups are indicated in the figure.

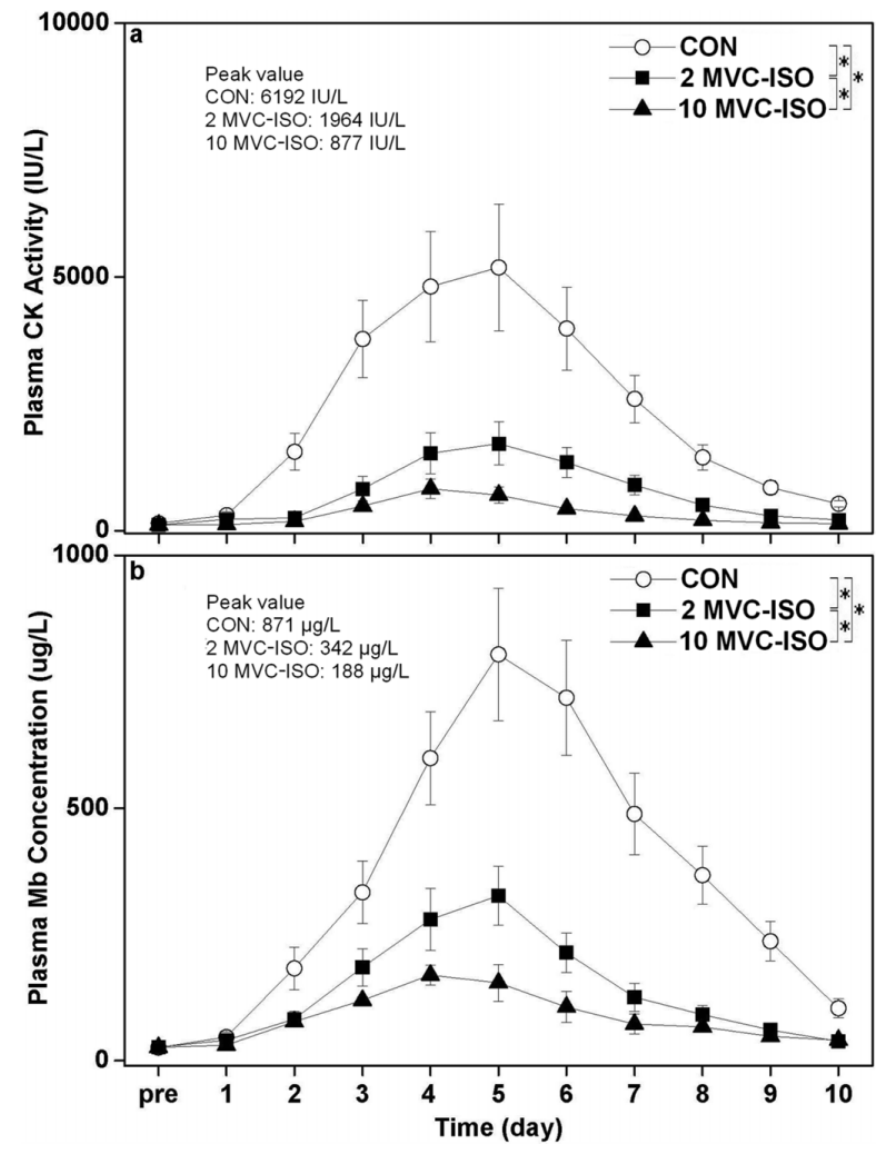

Compared with the control group, the increases in the echo intensity were significantly smaller for the $2 \mathrm{MVC}-\mathrm{ISO}$ and 10 MVC-ISO groups, and the 10 MVC-ISO group had significantly smaller increases than the 2 MVC-ISO group (Fig. $5 b$ ). The increases in the echo intensity at 5 days after exercise when the increases were maximum was attenuated by $7 \%$ for the 2 MVC-ISO group and by $13 \%$ for the 10 MVC-ISO group compared with the control group.

\section{Discussion}

The results showed that two or 10 maximal isometric contractions that were performed 2 days prior to maximal eccentric exercise, without affecting any indirect markers of muscle damage (Table 1), attenuated the magnitude of changes in the muscle damage markers and enhanced recovery of MVCCON peak torque and ROM following maximal eccentric exercise (Figs. 2-5). The results support the hypothesis that maximal isometric contractions at a long muscle length would attenuate muscle damage induced by the maximal ec-
Fig. 5. (a) Changes (mean \pm SEM) in muscle soreness with passive extension assessed by a $100 \mathrm{~mm}$ VAS and $(b)$ normalized changes in echo intensity of B-mode ultrasound images from the baseline (100\%, pre) to 1-10 days after eccentric exercise for the control group $(\mathrm{CON})$ and experimental groups that performed either two or 10 maximal isometric contractions (2 MVC-ISO and 10 MVC-ISO, respectively) prior to eccentric exercise. An asterisk (*) indicates a significant difference $(P<0.05)$ between groups based on the interaction effect shown by the two-way repeated-measures ANOVA. Peak muscle soreness values of the three groups are indicated in $a$. The echo intensity values at 5 days after exercise for the groups are shown in $b$.

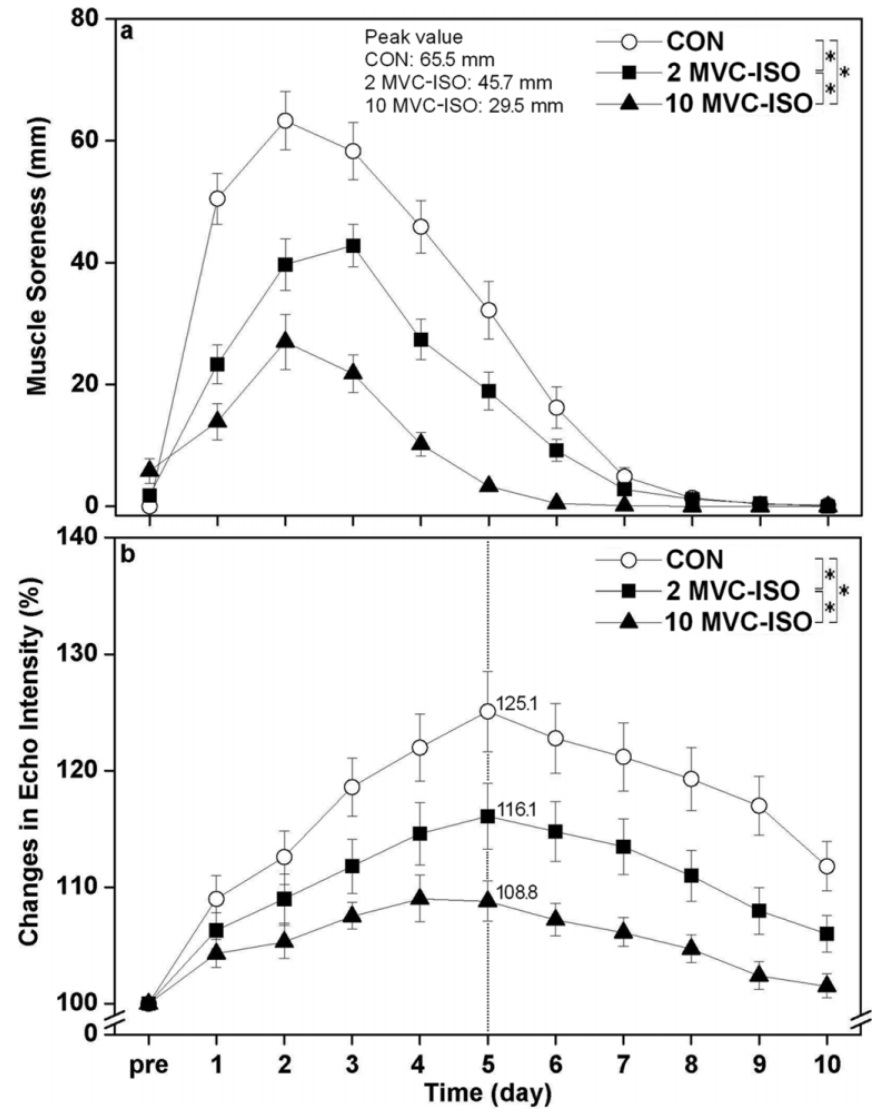

centric exercise, and 10 maximal isometric contractions would induce greater protective effect than two maximal isometric contractions.

No significant changes in any of the dependent variables following two or 10 maximal isometric contractions (Table 1) are likely to indicate that they did not induce muscle damage. Philippou et al. (2004) reported that two sets of 25 maximal isometric contractions of the elbow flexors at a long muscle length $\left(40^{\circ}\right.$ elbow flexion) resulted in a significant shift of optimum angle to a longer muscle length, decreases in maximal voluntary isometric strength, and relaxed elbow joint angle, as well as development of muscle soreness. It seems likely that the number of isometric contractions in the present study ( $n=2$ or 10 ) was not large enough to induce muscle damage.

The changes in the dependent variables following eccentric exercise for the control group are comparable with those reported following a similar eccentric exercise of the elbow flexors that was performed by "untrained" individuals for the 
first time without a familiarization session (e.g., Chen 2003; Chen and Nosaka 2006). If the changes in the dependent variables following eccentric exercise shown by the control group represent "normal" changes in the variables without prior isometric contractions, it is assumed that the changes in the dependent variables in the 2 MVC-ISO and 10 MVCISO groups reflect the effect of the isometric contractions on muscle damage induced by the eccentric exercise. It should be noted that the magnitude of protective effect conferred by two maximal isometric contractions was not one-fifths of that of 10 maximal isometric contractions, but the difference in the protective effect between two and 10 maximal isometric contractions was less two times. This suggests that the magnitude of the protective effect is not necessarily proportional to the number of maximal isometric contractions.

Chen et al. (2011a) showed that 30 low-intensity (10\% of maximal voluntary isometric contraction peak torque) eccentric contractions attenuated MVC-CON peak torque loss ( 5 days after exercise, 13\%), decrease in ROM (5 days after exercise, 66\%), increases in upper arm circumference (peak, $54 \%$ ), plasma CK activity (peak, 74\%) and Mb concentration (peak, 60\%), and muscle soreness (peak, 61\%) following 30 maximal eccentric contractions of the elbow flexors. These effects are similar to those conferred by 10 maximal isometric contractions in the present study. This may suggest that the effect of maximal isometric contractions on maximal eccentric contraction-induced muscle damage is stronger than that of submaximal eccentric contractions, because the smaller number of isometric contractions $(n=10)$ conferred a protective effect similar to that of a larger number of eccentric contractions $(n=30)$. It may be that intensity of contractions at a long muscle length rather than contraction mode is important for the induction of the protective effect.

The underpinning mechanisms of the protective effect against eccentric exercise-induced muscle damage are not fully understood. To explain possible mechanisms of the protective effect conferred by "eccentric contractions," McHugh (2003) categorized the potential adaptations as neural, mechanical, cellular, and others. Mackey et al. (2011) have recently reported that the extracellular matrix is strengthened following 180 isometric contractions evoked by electrical stimulation, and that muscle damage in the subsequent bout that was performed 28 days later was attenuated. It is not known whether any changes in the extracellular matrix are produced by isometric contractions. McArdle et al. (2004) found that the isometric contractions blunted CK release from the muscles after eccentric contractions and increased haemoxygenease-1 gene expression and stated that increased ROS production during the isometric contractions might play a role in the protective mechanisms. It is interesting to investigate whether these cellular adaptations are induced by only two or 10 maximal isometric contractions.

Several studies documented that one of the potential cellular adaptations for the protective effect is a longitudinal addition of sarcomeres, and this theory was indirectly supported by a shift in optimum angle to a longer muscle length (e.g., Proske and Morgan 2001; Philippou et al. 2004). However, the maximal isometric contractions in the present study did not shift the peak torque (optimum) angle (Table 1) but affected the changes in all indirect markers of muscle damage following maximal eccentric exercise (Figs. 2-5). If a shift of peak torque angle is a sensitive marker of changes in sarcomere number in series, the longitudinal addition of sarcomeres does not appear to be the protective mechanism conferred by isometric contractions.

This is the first study to demonstrate that only a few maximal isometric contractions at a long muscle length attenuate eccentric exercise-induced muscle damage against subsequent maximal eccentric exercise performed 2 days later. It is common that a familiarization session in which several maximal isometric contractions are performed is scheduled within a week (1-7 days) prior to eccentric exercise. Thus, it is interesting to examine how long the protective effect conferred by maximal isometric contractions lasts, whether maximal voluntary isometric contraction strength measures that are performed immediately before eccentric exercise still produce protective effect, and whether maximal isometric contractions at a short muscle length attenuate the magnitude of eccentric exercise-induced muscle damage. When designing a study to investigate eccentric exercise-induced muscle damage, it may be better not to include maximal isometric contractions at a long muscle length in a familiarization session. From a practical viewpoint, if it is required to minimize potential muscle damage induced by maximal eccentric exercise, performing a small number of maximal isometric contractions at a longer muscle length 2 days prior to the eccentric exercise is recommended. It appears that every isometric or eccentric contraction counts to change the susceptibility of muscles to eccentric exercise-induced muscle damage.

In conclusion, the present study showed that only two maximal isometric contractions at a long muscle length attenuated eccentric exercise-induced muscle damage and the protective effect was greater for 10 than for two maximal isometric contractions. Further studies are necessary to determine the mechanisms underlying the protective effect conferred by isometric contractions against eccentric exerciseinduced muscle damage.

\section{Acknowledgements}

The authors thank Ming-Ju Lin and Shueh-Chien Ko for their assistance with data collection and analysis. The authors declare that they have no potential conflict of interest.

\section{References}

Black, C.D., and McCully, K.K. 2008. Muscle injury after repeated bouts of voluntary and electrically stimulated exercise. Med. Sci. Sports Exerc. 40(9): 1605-1615. doi:10.1249/MSS. 0b013e3181788dbe. PMID:18685531.

Chapman, D.W., Newton, M., McGuigan, M.R., and Nosaka, K. 2008. Comparison between old and young men for responses to fast velocity maximal lengthening contractions of the elbow flexors. Eur. J. Appl. Physiol. 104(3): 531-539. doi:10.1007/ s00421-008-0806-7. PMID:18584196.

Chen, T.C. 2003. Effects of a second bout of maximal eccentric exercise on muscle damage and electromyographic activity. Eur. J. Appl. Physiol. 89(2): 115-121. doi:10.1007/s00421-002-0791-1. PMID:12665973.

Chen, T.C., and Nosaka, K. 2006. Responses of elbow flexors to two strenuous eccentric exercise bouts separated by three days. J. Strength Cond. Res. 20(1): 108-116. PMID:16503669.

Chen, T.C., Nosaka, K., and Sacco, P. 2007. Intensity of eccentric exercise, shift of optimum angle and the magnitude of repeated 
bout effect. J. Appl. Physiol. 102(3): 992-999. doi:10.1152/ japplphysiol.00425.2006. PMID:17138839.

Chen, T.C., Chen, H.L., Lin, M.J., Wu, C.J., and Nosaka, K. 2009. Muscle damage responses of the elbow flexors to four maximal eccentric exercise bouts performed every 4 weeks. Eur. J. Appl. Physiol. 106(2): 267-275. doi:10.1007/s00421-009-1016-7. PMID:19263073.

Chen, H.L., Nosaka, K., and Chen, T.C. 2011a. Muscle damage protection by low-intensity eccentric contractions remains for 2 weeks but not 3 weeks. Eur. J. Appl. Physiol. 112(2): 555-565. doi:10.1007/s00421-011-1999-8. PMID:21611825.

Chen, T.C., Lin, K.Y., Chen, H.L., Lin, M.J., and Nosaka, K. 2011 b. Comparison in eccentric exercise-induced muscle damage among four limb muscles. Eur. J. Appl. Physiol. 111(2): 211-223. doi:10. 1007/s00421-010-1648-7. PMID:20852880.

Clarkson, P.M., Nosaka, K., and Braun, B. 1992. Muscle function after exercise-induced muscle damage and rapid adaptation. Med. Sci. Sports Exerc. 24(5): 512-520. PMID:1569847.

Cohen, J. 1988. Statistical power analysis for the behavioral sciences. Lawrence Erlbaum Associates, Hillsdale, New Jersey.

Fridén, J., and Lieber, R.L. 2001. Eccentric exercise-induced injuries to contractile and cytoskeletal muscle fibre components. Acta Physiol. Scand. 171(3): 321-326. doi:10.1046/j.1365-201x.2001. 00834.x. PMID:11412144.

Hawes, M.R., and Martin, A.D. 2001. Human body composition. In Kinanthropometry and exercise physiology laboratory manual: tests, procedures and data. Edited by R.G. Eston and T. Reilly. Routledge, London. pp. 42-43.

Koh, T.J., and Brooks, S.V. 2001. Lengthening contractions are not required to induce protection from contraction-induced muscle injury. Am. J. Physiol. Regul. Integr. Comp. Physiol. 281(1): R155-R161. PMID:11404289.

Lauritzen, F., Paulsen, G., Raastad, T., Bergersen, L.H., and Owe, S.G. 2009. Gross ultrastructural changes and necrotic fiber segments in elbow flexor muscles after maximal voluntary eccentric action in humans. J. Appl. Physiol. 107(6): 1923-1934. doi:10.1152/ japplphysiol.00148.2009. PMID:19797695.

Lavender, A.P., and Nosaka, K. 2008. A light load eccentric exercise confers protection against a subsequent bout of more demanding eccentric exercise. J. Sci. Med. Sport, 11(3): 291-298. doi:10. 1016/j.jsams.2007.03.005. PMID:17707693.

Mackey, A.L., Brandstetter, S., Schjerling, P., Bojsen-Moller, J.,
Qvortrup, K., Pedersen, M.M., et al. 2011. Sequenced response of extracellular matrix deadhesion and fibrotic regulators after muscle damage in involved in protection against future injury in human skeletal muscle. FASEB J. 25(6): 1943-1959. doi:10.1096/ fj.10-176487. PMID:21368102.

McArdle, F., Spiers, S., Aldemir, H., Vasilaki, A., Beaver, A., Iwanejko, L., et al. 2004. Preconditioning of skeletal muscle against contraction-induced damage: the role of adaptations to oxidants in mice. J. Physiol. 561(1): 233-244. doi:10.1113/ jphysiol.2004.069914. PMID:15331678.

McHugh, M.P. 2003. Recent advances in the understanding of the repeated bout effect: the protective effect against muscle damage from a single bout of eccentric exercise. Scand. J. Med. Sci. Sports, 13(2): 88-97. doi:10.1034/j.1600-0838.2003.02477.x. PMID:12641640.

Nosaka, K., and Clarkson, P.M. 1996. Changes in indicators of inflammation after eccentric exercise of the elbow flexors. Med. Sci. Sports Exerc. 28(8): 953-961. doi:10.1097/00005768199608000-00003. PMID:8871903.

Paddon-Jones, D., Muthalib, M., and Jenkins, D. 2000. The effects of a repeated bout of eccentric exercise on indices of muscle damage and delayed onset muscle soreness. J. Sci. Med. Sport, 3(1): 3543. doi:10.1016/S1440-2440(00)80046-8. PMID:10839227.

Philippou, A., Bogdanis, G.C., Nevill, A.M., and Maridaki, M. 2004. Changes in the angle-force curve of human elbow flexors following eccentric and isometric exercise. Eur. J. Appl. Physiol. 93(1-2): 237-244. doi:10.1007/s00421-004-1209-z. PMID: 15293054.

Pizza, F.X., Koh, T.J., McGregor, S.J., and Brooks, S.V. 2002. Muscle inflammatory cells after passive stretches, isometric contractions, and lengthening contractions. J. Appl. Physiol. 92(5): 1873-1878. doi:10.1152/japplphysiol.01055.2001. PMID: 11960936.

Proske, U., and Morgan, D.L. 2001. Muscle damage from eccentric exercise: mechanism, mechanical signs, adaptation and clinical applications. J. Physiol. 537(2): 333-345. doi:10.1111/j.14697793.2001.00333.x. PMID:11731568.

Warren, G.L., Lowe, D.A., and Armstrong, R.B. 1999. Measurement tools used in the study of eccentric contraction-induced injury. Sports Med. 27(1): 43-59. doi:10.2165/00007256-19992701000004. PMID:10028132. 